\title{
Taenia solium cysticercosis
}

\author{
Héctor H García, MD, \\ Cysticercosis Unit, Instituto Nacional de Ciencias Neurologicas, Jr Ancash 1271, Barrios Altos, \\ Lima, Peru; Department of Microbiology, Universidad Peruana Cayetano Heredia, Lima
}

\section{Armando E Gonzalez, DVM, \\ Department of Public Health, School of Veterinary Medicine, Universidad Nacional Mayor de San Marcos, Lima; Department of International Health, Johns Hopkins School of Hygiene and Public Health, Baltimore, MD, USA}

Carlton A W Evans, MD, Imperial College of Science, Technology and Medicine, London, UK

Robert H Gilman, MD, and Department of Microbiology, Universidad Peruana Cayetano Heredia, Lima; Department of International Health, Johns Hopkins School of Hygiene and Public Health, Baltimore, MD, USA

\section{Cysticercosis Working Group in Peru}

\section{Abstract}

The larval stage of the pork tapeworm (Taenia solium) infects the human nervous system, causing neurocysticercosis. This disease is one of the main causes of epileptic seizures in many less developed countries and is also increasingly seen in more developed countries because of immigration from endemic areas. Little information is available on the natural evolution of taeniasis or cysticercosis. Available therapeutic measures include steroids, treatments for symptoms, surgery, and, more controversially, antiparasitic drugs to kill brain parasites. Efforts to control and eliminate this disease are underway through antiparasitic treatment of endemic populations, development of pig vaccines, and other measures.

Taenia solium infection and the resulting disease neurocysticercosis are endemic in less developed countries where pigs are raised as a food source. ${ }^{1}{ }^{2}$ Neurocysticercosis is common throughout Latin America, most of Asia, sub-Saharan Africa, and parts of Oceania, and is the greatest cause of acquired epilepsy worldwide. ${ }^{3}$ It is now increasingly diagnosed in more developed countries owing to immigration of tapeworm carriers from endemic zones. ${ }^{2}, 4$

$T$ solium has a complex two-host life cycle. Human beings are the only definitive host and harbour the adult tapeworm (taeniasis), whereas both people and pigs can act as intermediate hosts and harbour the larvae or cysticerci (figure 1).

\section{Taeniasis}

Taeniasis occurs only in the human host, after ingestion of undercooked pork infected with cysticerci. Although cysticercosis has been known for ages, its relation to the adult tapeworm was not clear until it was shown by Kuchenmaister in 1855; he fed condemned

\footnotetext{
Correspondence to: Dr Héctor H García (hgarcia@terra.com.pe) .

Conflict of interest statement

We have no financial interests in any company or competitor company that makes the products mentioned in this seminar.
} 
prisoners with cysticercosis-infected pork and recovered young tapeworms at autopsy. ${ }^{5}$ The larvae evaginate in the small intestine; the head (scolex) attaches to the mucosa and begins forming segments (proglottids). T solium has a scolex with four suckers and a double crown of hooks, a narrow neck, and a large strobila measuring 2-4 m and consisting of several hundred proglottids (figure 2). About 2 months after infection, gravid proglottids begin to detach from the distal end and are excreted in the faeces; each segment contains $50-60 \times 10^{3}$ fertile eggs. ${ }^{6}$

The worm attaches strongly to the mucosa of the upper small intestine by means of its suckers and hooks. The adult tapeworm causes only mild inflammation at the implantation site, ${ }^{7}$ without substantial damage to the intestine. ${ }^{4}$ Taeniasis is characterised by mild symptoms or none at all. ${ }^{4}$ Abdominal pain, distension, diarrhoea, and nausea have been attributed to tapeworm infestation, but there are no data from controlled experiments that demonstrate any association, and most patients seem to be free of symptoms. ${ }^{4},{ }^{6}$ In community settings many, if not most, carriers of $T$ solium will neither look for medical care nor notice the tapeworm segments in their stools. Conversely, most patients infected with Taenia saginata notice passage of proglottids, which are motile, more numerous, and larger than those of $T$ solium. $^{8}$ Identification of $T$ solium infections is important because of the risk of cysticercosis in the carrier or the immediate environment.

The frequency of autoinfection in individuals with taeniasis is not known. Dixon and Lipscomb ${ }^{9}$ noted that nearly $25 \%$ of patients with neurocysticercosis either had harboured or were harbouring a tapeworm. Up to $15 \%$ of patients harbour a tapeworm at the time of diagnosis of neurocysticercosis, ${ }^{10}$ and the proportion with tapeworms is directly related to the number of cerebral parasites, ${ }^{10},{ }^{11}$ which strongly suggests autoinfection. In other cases the tapeworm carrier can be found in the patient's household. ${ }^{12}$ Despite the poor sensitivity of stool examinations, parasitological screening of the patient and household members is recommended so that sources of infection can be detected and eliminated.

The lifespan of the adult $T$ solium is also unknown. Parasitology textbooks and reviews cite 20-25 years, on the basis of anecdotal cases. ${ }^{8},{ }^{13}$ Age-specific data from later studies suggest a much shorter lifespan, probably less than 5 years. ${ }^{14}{ }^{16}$

\section{Diagnosis of taeniasis}

Two problems hamper the diagnosis of infection with $T$ solium: the poor sensitivity of stool microscopy, and the morphological similarity between the eggs of $T$ solium and $T$ saginata. On the rare occasions when the worm scolex is found, the presence of the double crown of hooks (present only in $T$ solium) provides definite species identification. The morphology of the genitalia in mature proglottids or that of the gravid uterus in the distal proglottids can also enable the identification of species. ${ }^{4}$ Haematoxylin-eosin staining of histological sections of proglottids can help. ${ }^{17}$ Mature, gravid proglottids are rarely available, and morphological diagnosis of species on the basis of proglottid materials is technically difficult. In our experience, cleansing the intestine with a purge immediately before treatment improves the recovery of parasite material including the scolex, allowing species identification.

Visualisation of taenia eggs by microscopy was the only diagnostic method available until the early 1990s. Perianal scraping with adhesive tape (Graham's test) is highly sensitive for $T$ saginata but not for $T$ solium. ${ }^{18}, 19$ The best available diagnostic assay for intestinal taeniasis is a coproantigen detection ELISA, which detects taenia-specific molecules in faecal samples, demonstrating current tapeworm infection. ${ }^{20}$ It has sensitivity of about $95 \%$ and specificity greater than $99 \%$ and is an effective tool for epidemiological studies. ${ }^{15},{ }^{20}$ Coproantigen detection assays confirmed that microscopy was poorly sensitive, missing 60- 
$70 \%$ of cases. Diverse DNA-based assays, mainly to discriminate $T$ solium from $T$ saginata infections, ${ }^{17},{ }^{21}$ and a serological assay for specific identification of tapeworm carriers ${ }^{22}$ have been described lately.

\section{Treatment of taeniasis}

The two available drugs are niclosamide and praziquantel. Niclosamide is the drug of choice because it is not absorbed from the intestinal lumen. ${ }^{23}$ With praziquantel there is a small risk that asymptomatic viable brain cysts are affected by the drug in serum, causing neurological symptoms (headache, seizures). ${ }^{24}$ The usual dose is $2 \mathrm{~g}$ orally in a single dose for niclosamide, and $5-10 \mathrm{mg} / \mathrm{kg}$ orally in a sole dose for praziquantel. Both drugs have very limited marketing and are difficult to find.

\section{Human cysticercosis}

Cysticercosis is infection with the larval stage of the parasite. Human beings acquire cysticercosis through faecal-oral contamination with $T$ solium eggs from tapeworm carriers. $1,4,{ }^{25}$ Thus, vegetarians and other people who do not eat pork can acquire cysticercosis. ${ }^{26}$ Water, wind, flies, and other indirect means of infection play little part in transmission. ${ }^{27}$ Internal autoinfection by regurgitation of proglottids into the stomach in taeniasis has been proposed but not proven. ${ }^{1},{ }^{27}$

\section{Clinical presentation}

The invasive oncospheres (embryos) in the eggs are liberated by the action of gastric acid and intestinal fluids and actively cross the bowel wall, enter the bloodstream, and are carried to the muscles and other tissues. ${ }^{6},{ }^{28}$ At small terminal vessels, they establish and encyst as cysticerci (figure 3), reaching their definitive size of about $1 \mathrm{~cm}$ in $2-3$ months. ${ }^{29}$ Clinical manifestations depend on the affected organ; neurocysticercosis and ophthalmic cysticercosis are associated with substantial morbidity.

\section{Extraneural cysticercosis}

Outside the central nervous system, cysticercosis causes no major symptoms. Subcutaneous cysticercosis presents as small, movable, painless nodules that are most commonly noticed in the arms or chest. After a few months or even years, the nodules become swollen, tender, and inflamed, and then they gradually disappear. ${ }^{30}$ Subcutaneous cysticercosis is rare in Latin America but very common in Asia and Africa. Biopsy or fine-needle cytology ${ }^{31}$ of a subcutaneous nodule helps to confirm the diagnosis of cysticercosis infection. Muscular cysticercosis is a casual finding, appearing as dot-shaped or ellipsoidal calcifications following the muscle bundles in the thighs or arms, when radiography is done for an unrelated reason. In a classic series, $75 \%$ of patients with neurocysticercosis showed muscular calcifications after several years of radiographic follow-up, ${ }^{9}$ but this study has not been replicated with more sensitive CT scanning. In rare cases, very massive parasite burdens enlarge the patient's limbs (muscular pseudohypertrophy; figure 4). The heart is another occasional location of cysticerci, infected in about $5 \%$ of patients. ${ }^{32}$ As far as is known, cardiac cysticercosis is asymptomatic.

\section{Ophthalmic cysticercosis}

Although ophthalmic cysticercosis is much less common than neurocysticercosis (occurring in 1-3\% of all infections), $T$ solium is the most common intraorbital parasite. ${ }^{33}$ Intraocular cysts are most frequently found floating freely in the vitreous humour or in the subretinal space. Visual disturbance is related to the degree of damage to retinal tissue or the development of chronic uveitis. ${ }^{34}$ Cysticercosis may also present in the anterior chamber or affect the conjunctiva or extraocular muscles. Some individuals with massive infections 
have cysts in the retro-ocular space, affecting the optic nerve or causing proptosis. ${ }^{35}, 36$ Orbital ultrasonography is a valuable and harmless diagnostic method. ${ }^{33}, 34$ Visual loss can also be related to cerebral cysticercosis causing papilloedema, hydrocephalus, or chiasm compression..$^{37}$

\section{Neurocysticercosis}

The parasite commonly infects the central nervous system, causing neurocysticercosis, a pleiomorphic clinical disorder. After entering the central nervous system, cysticerci are viable and elicit few inflammatory changes in the surrounding tissues. Cysticerci may remain for a long time in this stage, protected by the blood-brain barrier ${ }^{6}, 38,39$ and active immune-evasion mechanisms by the cysticerci. ${ }^{6}$ After a variable and unknown time (estimated to be several years on the basis of classic studies in English soldiers returning from India), ${ }^{9},{ }^{30}, 40,41$ the parasite degenerates with associated immune-mediated inflammation. Cysticerci cause symptoms because of mass effect or by blocking the circulation of cerebrospinal fluid, but most symptoms in neurocysticercosis are the direct result of the inflammatory process that accompanies cyst degeneration. Clinical manifestations are thus related to individual differences in the number, size, and topography of lesions and in the severity of the host's immune response to the parasites. ${ }^{28}$ Symptoms and signs are varied and non-specific.

Epileptic seizures are the commonest presentation of neurocysticercosis and generally represent the primary or sole manifestation of the disease. Seizures occur in 50-80\% of patients with parenchymal brain cysts or calcifications but are less common in other forms of the disease. ${ }^{3},{ }^{42},{ }^{43}$ In endemic regions, recent onset of seizures in otherwise healthy teenage, young adult, or middle-aged individuals strongly suggests neurocysticercosis. ${ }^{44}$ Most of these patients are normal on neurological examination. A series including mostly patients with mild forms of infection ${ }^{45}$ showed that about $50 \%$ of patients with neurocysticercosis presenting a seizure have further seizures (epilepsy). The proportion of relapses in patients with more severe forms of disease is expected to be higher.

Neurocysticercosis also presents with intracranial hypertension, hydrocephalus, or both in $20-30 \%$ of cases (the proportion varies according to the origin of the cases, higher in neurosurgical series). This syndrome is related to the location of parasites in the cerebral ventricles or basal cisterns, blocking the circulation of cerebrospinal fluid, and is caused by several different mechanisms - the presence of the parasite itself, ependymal inflammation, or residual fibrosis. ${ }^{46}, 47$

Occasionally, a cyst grows larger than the usual $1-2 \mathrm{~cm}$ and acts in the same way as a tumoral mass (giant cyst). ${ }^{48},{ }^{49}$ These giant cysts compress adjacent cerebral structures, causing localised deficits and intracranial hypertension. Cyst growth occurs most frequently in the subarachnoid space around the sylvian fissure or in the basal cisterns. Motor deficits can also arise because of oedema secondary to cyst degeneration, or as a result of stroke complicating neurocysticercosis. Stroke is more frequent in subarachnoid neurocysticercosis than in intraparenchymal infections. It consists mostly of deep lacunar infarcts resulting from endarteritis of small penetrating arteries, whereas occlusion of large vessels is rare. ${ }^{50}$

In children and teenagers, an acute encephalitic presentation can happen; it is more likely in female than male patients. ${ }^{51}$ This disorder is due to intense inflammatory reaction of the host to a massive parasite infection, with pronounced intracranial hypertension. Massive non-encephalitic forms also occur, presenting with occasional seizures, episodic intracranial hypertension, or mild cognitive dysfunction. 
Compromise of the spine occurs in about $1 \%$ of cases of neurocysticercosis, presenting with compressive manifestations. Cysts locate mostly in the subarachnoid space, although intramedullary cysts are found rarely. ${ }^{52}$

There seems to be geographical variation in clinical manifestations. In some Asian countries, almost all patients with neurocysticercosis present with a single enhancing brain lesion, and a few have very massive infections with hundreds of cysts. Conversely, in Latin America, the most frequent presentation of neurocysticercosis is a few viable cysts without signs of inflammation.

\section{Pathology}

Cysts are uniformly rounded or oval vesicles, varying in size from a few millimetres to 1-2 $\mathrm{cm}$ (in rare cases a growing cyst reaches several centimetres in diameter). The most common location is in the cerebral hemispheres, mainly at the junction of grey and white matter. Cysts can be found in the cerebellum, ventricles, brainstem, subarachnoid space, basal cisterns, and spine. The number ranges from one to more than a thousand. On gross examination, no variations are observed in the nervous parenchyma surrounding viable cysts. ${ }^{32}, 53$

Vesicles vary in contents according to their evolutionary stage. Viable cysts have a translucent membrane through which the scolex is visible as a small 2-3 mm nodule. When the cyst starts to degenerate, the vesicular fluid becomes opaque and dense, and the edges of the cyst become irregular and shrink. Later, calcification starts in the cephalic portion and progresses to the vesicular wall, to leave a round, whitish, calcified nodule. In rare cases, all the evolutionary phases can be seen in the same individual. ${ }^{54}$

Intraventricular cysticercosis is generally single and free inside the cavities. Infrequently, the cyst moves from one ventricular cavity to another. ${ }^{55},{ }^{56}$ Classically, cysts are described as locating more frequently in the lower cavities: most frequently in the fourth ventricle, less commonly in the third, and least frequently in the lateral ventricles ${ }^{57}$ Intraventricular parasites can block circulation of cerebrospinal fluid or produce inflammation of the ependyma and choroid plexus.

The racemose form is a large translucent vesicle, frequently lobulated, without a scolex, which develops in the basis of the brain or in the ventricles. ${ }^{32}, 53,{ }^{58}$ Sometimes several small vesicles surround a pedicle attached to the pia mater like a bunch of grapes (figure 5), hence the name. As vesicles grow in number and adherences, they take over the basal cisterns, giving an infiltrative appearance. The racemose form is associated with high mortality because of its association with obstructive hydrocephalus. ${ }^{58}$

\section{Diagnosis}

\section{Serology}

A finding of eosinophils in the cerebrospinal fluid suggests the diagnosis of neurocysticercosis. Other routine laboratory tests scarcely contribute, and thus the diagnosis rests on serology and neuroimaging. Although both are highly sensitive and specific, perfect correlation should not be expected since their approaches differ.

Until recently, serological diagnosis of cysticercosis was less than satisfactory. The most commonly used ELISA cross-reacts with Hymenolepis nana and Echinococcus granulosus, which are common cestode infections. ${ }^{59},{ }^{60}$ For this reason, it is much more useful when applied to samples of cerebrospinal fluid than of serum, with the drawbacks of the invasiveness and pain associated with the lumbar puncture. The enzyme-linked immunoblot 
assay was originally reported to have sensitivity of $98 \%$ and specificity of $100 \%,{ }^{61}, 62$ and it performs much better than the ELISA in clinical settings. ${ }^{63},{ }^{64}$ Its sensitivity in patients with only one degenerating cysticercus or calcified lesions only is much lower. ${ }^{65}$ In hospital settings, antibody can be seen to persist for a long time after the death of parasites, ${ }^{66}$ and thus a positive antibody test in patients with calcified cysticercosis only is a common finding and should not be interpreted as indicating the presence of live parasites. This assay requires more reagents, advanced equipment, and highly trained personnel for antigen purification and assay performance than does the ELISA. When available, however, immunoblot is an excellent instrument for diagnosis and management. ${ }^{44},{ }^{63},{ }^{64}$ Since the physician needs to know the number, location, size, and stage of intracranial parasites, serology mostly has a screening or confirmatory role and should be used in conjunction with neuroimaging. Antigen detection assays can detect live parasites and thus direct therapeutic decisions or monitoring. ${ }^{67},{ }^{68}$ Some, based on monoclonal antibodies, perform well in comparison with other available tests on cerebrospinal-fluid samples. ${ }^{68}{ }^{80}$ There is limited evidence on sensitivity or specificity with serum samples.

\section{Neuroimaging}

Because the important features are the number, size, and location of lesions, radiography has always been crucial for diagnosis of neurocysticercosis. ${ }^{40}$ Initially, skull and soft-tissue radiographs showed calcifications, and arteriography and pneumoencephalography (both dangerous techniques no longer used for this purpose) showed lesions causing mass effect and hydrocephalus. Lately, computer-based imaging procedures have enabled visualisation of the brain and other intracranial soft structures. Currently used techniques include CT and MRI.

CT has been claimed to have sensitivity and specificity of over $95 \%$ for the diagnosis of neurocysticercosis, ${ }^{28}$ although CT images are rarely pathognomonic for this disease. ${ }^{71}$ The availability of antiparasitic treatments and serial CT studies has allowed the description of imaging changes throughout the involution process. Cysts appear as hypodense images, with well-defined edges, and commonly a hyperdense nodule inside the cyst shows the parasite's scolex. ${ }^{28}$ Parasite degeneration initially appears as contrast enhancement of the edges of the cyst and perilesional oedema, resulting from the inflammatory reaction in the surrounding tissue. ${ }^{72}$ In later stages, the cyst becomes isodense to the parenchyma but appears after the administration of contrast, enhancing as a nodule or a ring. This image, called enhancing lesion or cysticercus granuloma is barely visible in precontrast images, and corresponds to the late degenerative phase (no longer viable). The differential diagnosis of this entity in endemic regions is extremely difficult because of the endemicity of tuberculosis and neurocysticercosis (panel 1). Patients with a sole enhancing lesion in the brain due to neurocysticercosis are seronegative because the parasite is already dead or because a sole parasite does not elicit a strong antibody response, ${ }^{1}$ and many patients with tuberculoma do not have detectable tuberculosis in the lungs or in any other location to confirm the diagnosis.

After this phase, the cysticercus becomes a calcified scar, which normally does not enhance with the contrast substance. However, contrast enhancement and perilesional oedema can be seen around old, calcified lesions and are associated with symptom relapses. ${ }^{57},{ }^{73}{ }_{-} 76$ The sensitivity of CT is much lower for ventricular or cisternal forms of the disease.

Intraventricular cysticercosis presents with obstructive hydrocephalus, and only indirect signs such as cavity enlargement or deformation are seen on CT.

MRI is the most accurate technique to assess the degree of infection, the location, and the evolutionary stage of the parasites (figure 6). It visualises well the perilesional oedema and the degenerative changes of the parasite, as well as small cysts or those located in the 
ventricles, brainstem, cerebellum, eye, and basal racemose vesicles. CT, however, is more sensitive for the detection of calcifications. ${ }^{77}$ The main disadvantages of MRI are its high cost and scarce availability.

A set of objective diagnostic criteria has been proposed. ${ }^{78}$ Absolute criteria include histological demonstration of the parasite, cystic lesions with scolex on neuroimaging, or direct visualisation of ocular cysts; major criteria include suggestive lesions on neuroimaging, positive serum immunoblot, resolution of cysts after antiparasitic therapy, or spontaneous resolution of enhancing lesions; minor criteria are compatible lesions on neuroimaging, compatible clinical manifestations, positive cerebrospinal-fluid ELISA, or cysticercosis outside the central nervous system; and epidemiological criteria include household contact, living in an endemic area, or travel to endemic areas. Combinations of these criteria provide different degrees of diagnostic certainty.

\section{Prognosis and natural evolution}

Panel 2 shows research needs in $T$ solium infection. There are few data on the natural evolution of neurocysticercosis, and those available are from historical controls in open treatment trials. As far as is known, the evolution of intraparenchymal neurocysticercosis follows a favourable course with degeneration of parasites and formation of residual calcified scars. ${ }^{79}$ When the parasites locate in the subarachnoid space or the ventricles, the morbidity and mortality are much higher because of parasite growth, intracranial hypertension, arachnoiditis, blockage of cerebrospinal-fluid pathways, hydrocephalus, and other complications. ${ }^{49}, 80,81$

\section{Treatment}

Cysticercosis outside the nervous system is a benign disorder and does not merit specific treatment. Neurocysticercosis, however, is associated with substantial morbidity and mortality. Until 1978, the only treatments available were surgery for cyst excision or ventricular shunts or steroids to decrease inflammation. Praziquantel, first used in porcine cysticercosis, was the first effective specific antiparasitic drug. ${ }^{82}{ }^{84}$ Later, albendazole added a cheaper and more effective alternative. ${ }^{85},{ }^{86}$ Transient worsening of neurological symptoms can be expected during antiparasitic therapy, secondary to the perilesional inflammatory reaction. In most cases, symptoms are limited to mild to moderate headache and are easily controlled with steroids. Although antiparasitic agents in neurocysticercosis have been accepted by most of the medical community, some believe that, since the parasite starts to cause symptoms at the time of its death, the use of parasiticidal drugs leads to an unnecessary increase in the inflammatory process. ${ }^{79},{ }^{87}$ The issue led to heated discussion. ${ }^{88} 90$ The main argument is whether antiparasitic treatment or natural involution of a cyst will lead to reduced scarring and thus improved prognosis in terms of epilepsy evolution.

Many reports have been published on the use of antiparasitic treatment in neurocysticercosis. $.^{82} 86,90 \_94$ However, non-treatment comparison groups were included in only four studies, three of which included patients with enhancing lesions (parasites that have already degenerated). A summary of controlled studies can be found in the Cochrane Library, ${ }^{95}$ although no overall conclusion can be reached because the types of disease and the findings differ substantially. Two double-blind, placebo-controlled trials assessed patients with a sole enhancing lesion. Padma and colleagues ${ }^{93}$ found similar resolution rates on 3-month follow-up CT in groups assigned albendazole or placebo. ${ }^{93}$ By contrast, Baranwal and co-workers ${ }^{91},{ }^{92}$ found better resolution on imaging and fewer seizures in the albendazole group than in controls during follow-up. A third double-blind, placebocontrolled trial in India compared the evolution of parenchymal neurocysticercosis lesions (including cysts and enhancing lesions) on CT at 3 months after treatment ${ }^{94}$ and showed 
similar resolution rates. The only controlled trial in non-enhancing intraparenchymal cysts has been an open-label study comparing radiological and clinical (seizure relapses) evolution between patients treated with albendazole, praziquantel, or no antiparasitic therapy. ${ }^{90}$ All three groups received prednisone. The study found no differences in the proportions of patients free of cysts at 6 months and 1 year after treatment, or in the relative reduction in numbers of cysts and no difference in the proportion of patients free of seizures during the entire follow-up.

Antiparasitic treatment may be unnecessary or even contraindicated in some cases. Without doubt however, there are subgroups of patients with neurocysticercosis who not only benefit from antiparasitic therapy but also might undergo progression of disease and even die if not treated, such as those with giant cysts or subarachnoid cysticercosis. ${ }^{48},{ }^{49}$ Similarly, complications in the treatment of neurocysticercosis with antiparasitic drugs can be severe, but they are very rare. Until a prospective, randomised study has been completed, a simple summary is that antiparasitic agents are effective to destroy cysticerci in the human brain, at the cost of acute inflammation. Whether this is the most beneficial option for patients with intraparenchymal cysticercosis in the long term is not yet clear. The currently accepted schemes are either 8 days of albendazole treatment $(15 \mathrm{mg} / \mathrm{kg}$ daily) with simultaneous administration of steroids, or 15 days of praziquantel (50 mg/kg daily). ${ }^{96}$ Shorter schemes of 1 day of praziquantel or 3 days of albendazole seem effective for patients with only one lesion, but not for those with many cysts. ${ }^{97}, 98$

A panel of experts analysed the current consensus and disagreements in the management of neurocysticercosis. ${ }^{99}$ Their main conclusions were that therapeutic decisions should be adapted to the individual and should be based on the number, location, and viability of the parasites within the nervous system; that growing cysticerci should be actively managed by either antiparasitic drugs or surgical excision; that the management of intracranial hypertension secondary to neurocysticercosis should take a high priority; and that adequate management of seizures should be ensured. Specifically, they agreed on the management of patients with moderate infections and viable cysts (antiparasitic treatment, with steroids); calcified cysticercosis (no antiparasitic treatment); ventricular cysticercosis (neuroendoscopic removal, when available); subarachnoid cysts, including giant cysts or racemose cysticercosis, and chronic meningitis (antiparasitic treatment with steroids, ventricular shunt if there is hydrocephalus); cysticercotic encephalitis (no antiparasitic treatment, high-dose steroids, and osmotic diuretics); hydrocephalus with no visible cysts on neuroimaging (ventricular shunt, no antiparasitic treatment); spinal cysticercosis, intramedullary or extramedullary (primarily surgical); or ophthalmic cysticercosis (surgical resection of cysts). There were disagreements about the use of antiparasitic drugs (considered unnecessary or of high risk by some experts) in patients with only one or a few viable cysts, patients with massive infections with viable cysts, or patients with many degenerating cysts. ${ }^{99}$

Treatment of symptoms has an important role in the management of neurocysticercosis. Seizures generally respond well to first-line antiepileptic drugs, ${ }^{43},{ }^{100}$ but complete withdrawal of antiepileptic therapy is difficult to achieve. ${ }^{100}$ Steroids, dexamethasone or prednisone, are helpful in oedema or intracranial hypertension.

\section{Porcine cysticercosis}

In places with inadequate disposal of human faeces, pigs ingest stools containing $T$ solium eggs. Cysticerci lodge anywhere in the body of the pig, most commonly in the muscle and subcutaneous fat. Pigs with cysts in the brain are a subset of those with more cysts in the carcass (Cysticercosis Working Group in Peru 2002, unpublished data). Although some pigs 
have massive infections, porcine cysticercosis is rarely associated with symptoms of any kind. Most pigs are killed before the age of 9 months, which is too short a time for the cysts to reach the degenerative stage that is associated with symptoms in human beings.

An inexpensive treatment for porcine cysticercosis might increase the value of pigs and block transmission of infection. A veterinary benzimidazole, oxfendazole, is more than $95 \%$ effective in killing the cysts in the pig when given in a single dose of $30 \mathrm{mg} / \mathrm{kg} .{ }^{101}{ }_{-}{ }^{103} \mathrm{This}$ drug has not yet been tested in human beings.

Immunity to the oncosphere stage plays a central part in regulation of transmission of taeniid cestodes, and oncosphere-based vaccines are highly protective for Tovis, Echinococcus granulosus, and T saginata. ${ }^{104}$ Partial protection has been achieved by vaccination of healthy pigs with $T$ solium oncospheral antigens. ${ }^{105 \_107}$

\section{Epidemiology}

Cysticercosis affects thousands of individuals in less developed countries ${ }^{1,}, 3$ and in more developed countries with a high rate of immigration from endemic areas. ${ }^{2},{ }^{4}$ In endemic countries taeniasis/cysticercosis is extremely common, and neurologically symptomatic individuals, although many, represent only the tip of the iceberg. In most endemic villages more than $10 \%$ of the general population are seropositive, and the proportion can reach $25 \%$. In population-based studies, $10-18 \%$ of asymptomatic individuals have CT features that suggest neurocysticercosis, mainly brain calcifications in seronegative individuals. $108 \_111$

Transient seropositive reactions ${ }^{112}$ and common cases of asymptomatic calcified neurocysticercosis ${ }^{108}{ }_{-} 111$ are consistent with a threshold under which parasite destruction occurs, potentially determined by the number of parasites, the immune status of the host, the age at infection, or any combination of these factors. Animal models suggest that the host's immune response can resolve mild infections at early stages. ${ }^{113}$ If this resolution occurs in human neurocysticercosis, it could explain the frequency of degenerating cysts clustered in younger ages, the relation to infections with a single parasite (90\% of cases with only degenerating cysts), and the frequency in India, where, because of vegetarian habits, direct exposure to tapeworm carriers is less frequent. ${ }^{114}$ Patients with viable cysts only would represent cases in which the parasites survive and establish.

Few data are available on the epidemiology of adult tapeworm infections. Up to $6 \%$ of the population in endemic villages may harbour adult $T$ solium tapeworms at a given time. $.^{15}, 115$ The few existing community studies in taeniasis, done in Guatemala ${ }^{14},{ }^{15}, 116$ and Peru, ${ }^{16}$ show that tapeworm infections are more common in younger than older individuals, especially in the female population. Consistently, cases of intestinal taeniasis cluster in houses, ${ }^{14}$ probably as a result of similar food consumption habits. Clustering of infected pigs or seropositive human beings around tapeworm carriers has also been shown. ${ }^{14},{ }^{16}$

Domestic pig raising, taeniasis, and human cysticercosis are intimately inter-related. Many farmers in less developed countries cannot afford a cow but can buy a few pigs. These animals are cheap and easily marketable, becoming a convenient source of meat or money. Even better, no investment is needed to feed them, since free pigs roam around and eat pasture and garbage. In endemic areas, few pigs go through the formal slaughterhouse system; moreover, peasants used to screen their pigs for cysticercosis by examining their tongues ${ }^{117}$ before taking them to the slaughterhouse. ${ }^{118}$ Thus, abattoir prevalence statistics are probably a gross underestimation of the real rates. ${ }^{118}$ Serology has proven useful to detect infected animals for epidemiological purposes. The rates of porcine infection vary, but in endemic regions $30-60 \%$ of pigs are seropositive. ${ }^{117},{ }^{119}$ Studies in pigs have 
provided important data: the high correlation between human and porcine prevalence, the use of sentinel pigs to monitor transmission, and the potential use of oxfendazole for the control.

\section{Cysticercosis and epilepsy}

Epilepsy is more prevalent in less developed than in more developed countries. ${ }^{120}$ Rates such as 17 per 1000 in Ecuador, ${ }^{121} 21$ per 1000 in Colombia, ${ }^{122}$ and 37 per 1000 in Nigeria ${ }^{123}$ are three to six times higher than those in more developed countries. ${ }^{3}$ Serological studies in India, ${ }^{42}$ South Africa, ${ }^{124}$ Mexico, ${ }^{108}$ and Peru ${ }^{125}$ suggest that the higher rates of epilepsy are due mainly to neurocysticercosis. In Mexico ${ }^{126}$ and Peru, ${ }^{44} 12 \%$ of neurological hospital beds are occupied by patients with neurocysticercosis. Similar surveys in neurological centres show neurocysticercosis in 30-50\% of epileptic individuals, compared with less than $5 \%$ of individuals attending with other neurological symptoms. $42,125,127$ When correctly compared, seroprevalence is consistently much higher in neurological patients than in the relevant general populations. The risk of epilepsy in seropositive individuals is twice to three times that in seronegative controls. ${ }^{108},{ }^{128}$ The risk increases further for specific subgroups (people with late-onset epilepsy, for example). There are no data on the risk of neurological symptoms developing in seropositive individuals in the community.

\section{Cysticercosis in non-endemic countries}

In the USA, neurocysticercosis is common in hospitals treating large Hispanic populations in areas such as Los Angeles, San Diego, New Mexico, and Houston. ${ }^{2},{ }^{4}$ The number of cases in the USA (including people born in the country) is increasing, probably as a result of both improved diagnosis and increased immigration of individuals infected with $T$ solium. ${ }^{4}$ A cluster of cysticercosis cases arose in an Orthodox Jewish community in Brooklyn, New York. The only risk to this population was their exposure to Latin-American domestic workers who were probably infected with $T$ solium tapeworms. ${ }^{26}$ In a recent study in accident and emergency departments of patients who underwent neuroimaging because of a seizure, neurocysticercosis was found in 10\% in Los Angeles and 6\% in New Mexico. ${ }^{129}$ Cases of neurocysticercosis are now also diagnosed more frequently than before in Europe, Australia, and other non-endemic areas. ${ }^{130}, 131$

\section{Economic burden}

Neurocysticercosis affects mainly older children and adults, so the estimated economic consequences due to chronic disability are heavy. Flisser ${ }^{126}$ estimated a cost of US $\$ 15$ million per year only for hospital admission of cases of newly diagnosed neurocysticercosis in Mexico. There are no figures available on the maintenance cost of antiepileptic-drug therapy in epilepsy due to neurocysticercosis, or other long-term costs. Patients with calcified cysticercosis can have seizures or other neurological morbidity persisting for years after they are deemed cured. $T$ solium not only produces a severe disease ${ }^{1}$ but also causes widespread economic losses to the pig industry. ${ }^{132}$ In Mexico, for example, porcine cysticercosis caused loss of more than half the national investment in swine production, ${ }^{133}$ and the losses occasioned by the destruction of meat are estimated at $\$ 43$ million per year. 126

\section{Control of taeniasis and cysticercosis}

$T$ solium is transmitted mainly in rural areas where pigs have access to untreated human sewage or faeces and infected pork is widely available. An estimated 400000 people have symptomatic neurocysticercosis in Latin America alone. ${ }^{134}$ More developed countries eradicated cysticercosis by improving sanitation and controlling domestic pig-raising. ${ }^{135}, 136$ 
Since little socioeconomic development in endemic areas is expected in the near future, intervention measures for control and eradication are urgently needed.

To date, no intervention has achieved sustained interruption of transmission. Abattoir inspection and confiscation is the only official diagnostic method in most endemic countries.

12 In most of these areas, the majority of pigs are killed clandestinely in any case. Since only a few cuts are made in each carcass to preserve its commercial value, slaughterhouse inspection probably misses most mild infections. This system drives farmers to slaughter pigs illegally and does not stop the distribution of infected meat. ${ }^{118}$

Only the tapeworm carriers and the infected pigs are important in terms of transmission. Individuals with neurocysticercosis are a health concern; but unless they also carry an intestinal tapeworm, they do not pose a public-health risk. Rates of human taeniasis can be decreased either by detection and treatment of the tapeworm carriers, or by treatment of the whole population. ${ }^{12},{ }^{115},{ }^{137}$ Transmission can also be blocked if the sale and consumption of infected pork is prevented by slaughterhouse inspection. ${ }^{12}$ Health education alone has also been tested in Mexico, with promising but incomplete results. Knowledge about the disease improved substantially, but practices related positively or negatively to risk (hand-washing, defecating in fields, corralling of pigs) remained unchanged. In favour of health education is the long-term effect of acquired knowledge. ${ }^{138},{ }^{139}$ Porcine infection can be addressed either by mass anthelmintic treatment ${ }^{101},{ }^{102},{ }^{140}$ or in the future, if an effective vaccine becomes available, by immunisation of the pig population. ${ }^{106},{ }^{141},{ }^{142} \mathrm{~A}$ high-cost vaccine would undoubtedly be an impediment for a vaccine strategy, since the target population is rural endemic villages. Any selected combination of interventions would need to ensure community cooperation to achieve sustainable control.

\section{Search strategy}

This seminar is based on papers published in the past 15 years in English, Spanish, or Portuguese selected from MEDLINE by use of the PubMed system with keywords "cysticercosis", "neurocysticercosis", "Taenia solium", "epilepsy", and "seizures". Older articles were selected from the private collections of the authors and the archives of the Cysticercosis Working Group in Peru.

\section{Panel 1: Differential diagnosis of neurocysticercosis on neuroimaging}

\section{Sole non-enhancing cystic lesion}

Hydatid disease

Arachnoid cysts

Porencephaly

Cystic astrocytoma

Colloid cyst (third ventricle)

Several non-enhancing cystic lesions

Multiple metastases

Hydatid disease (rare)

\section{Enhancing lesions}

Tuberculosis 


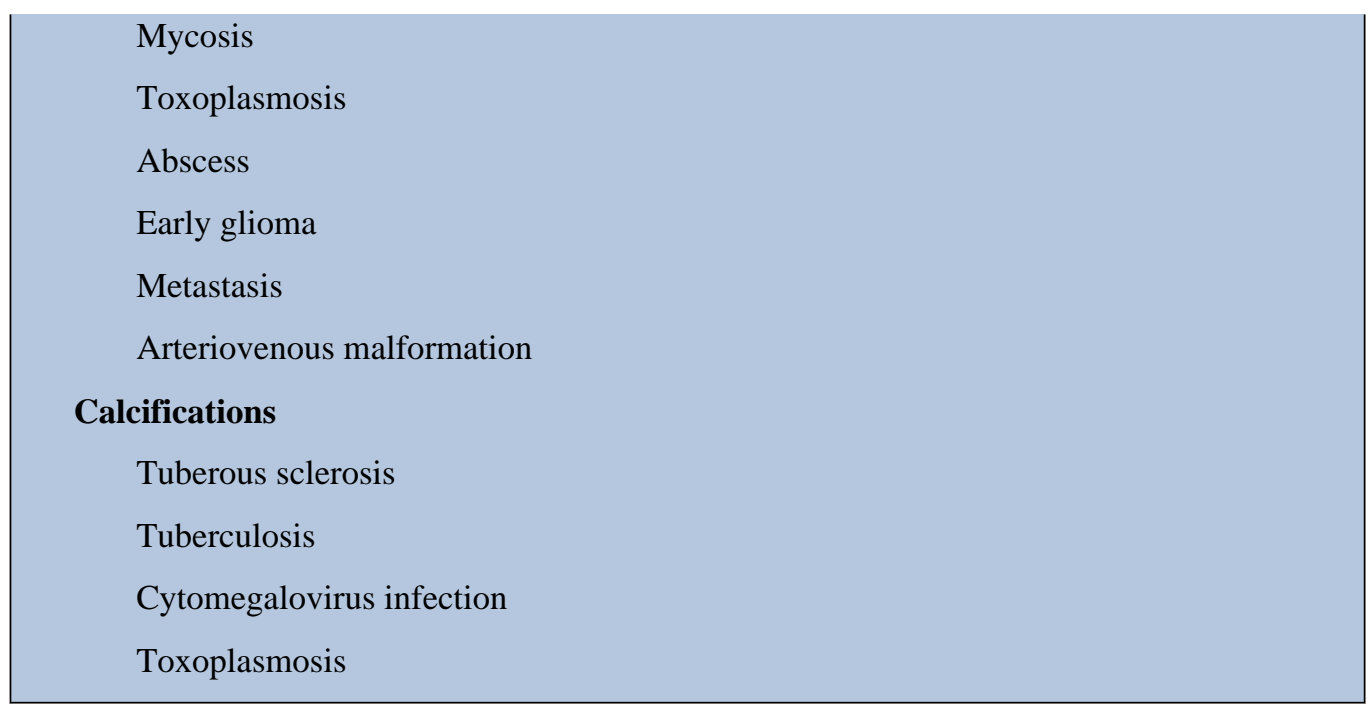

\section{Panel 2: Research needs in $T$ solium infection}

\section{Clinical}

Improved knowledge of natural history

Concrete determination of benefits and specific indications of antiparasitic therapy in neurocysticercosis

Testing of new antiparasitic and anti-inflammatory agents

\section{Immunological}

Development of field-applicable, specific assays for human taeniasis

Development of field-applicable, specific assays for viable cysticercosis

\section{Prevention and control}

Systematic assessment of efficacy and effectiveness of all potential intervention measures (including pig vaccines)

Estimation of infection and disease burden attributable to neurocysticercosis

Estimation of economic losses due to porcine cysticercosis

\section{Acknowledgments}

Our work is supported by the National Institute of Allergy and Infectious Diseases, National Institutes of Health, Bethesda, MD, USA; the Office of Orphan Products Development, Food and Drug Administration, MD, USA, and the Wellcome Trust, London, UK. Figures 3b, 6a, and 6b were facilitated by the Department of Pathology of the Institute of Ciencias Neurologicas, Lima, Peru, and Hermes Escalante, ESCALABS, Trujillo, Peru. The sponsors had no role in the preparation of this review.

\section{References}

1. Garcia HH, Del Brutto OH. Taenia solium cysticercosis. Infect Dis Clin North Am. 2000; 14:97119. [PubMed: 10738675]

2. White AC Jr. Neurocysticercosis: updates on epidemiology, pathogenesis, diagnosis, and management. Annu Rev Med. 2000; 51:187-206. [PubMed: 10774460] 
3. Commission on Tropical Diseases of the International League Against Epilepsy. Relationship between epilepsy and tropical diseases. Epilepsia. 1994; 35:89-93. [PubMed: 8112262]

4. Schantz, PM.; Wilkins, PP.; Tsang, VCW. Immigrants, imaging and immunoblots: the emergence of neurocysticercosis as a significant public health problem. In: Scheld, WM.; Craig, WA.; Hughes, JM., editors. Emerging infections 2. ASM Press; Washington: 1998. p. 213-41.

5. Henneberg, R. Die tierischen parasiten des zentralnervensystem. In: Lewandowsky, M., editor. Handbuch der neurologie. Springer; Berlin: 1912. p. 642-83.

6. Flisser, A. Taeniasis and cysticercosis due to T solium. In: Sun, T., editor. Progress in clinical parasitology. CRC Press; New York: 1994. p. 77-116.

7. Merchant MT, Aguilar L, Avila G, Robert L, Flisser A, Willms K. Taenia solium: description of the intestinal implantation sites in experimental hamster infections. J Parasitol. 1998; 84:681-85. [PubMed: 9714193]

8. Pawlowski Z, Schultz MG. Taeniasis and cysticercosis (Taenia saginata). Adv Parasitol. 1972; 10:269-343. [PubMed: 4559145]

9. Dixon, HB.; Lipscomb, FM. Cysticercosis: an analysis and follow-up of 450 cases. Medical Research Council; London: 1961.

10. Gilman RH, Del Brutto OH, Garcia HH, Martinez M. Prevalence of taeniosis among patients with neurocysticercosis is related to severity of infection. Neurology. 2000; 55:1062. [PubMed: 11061275]

11. Garcia HH, Del Brutto OH. Heavy nonencephalitic cerebral cysticercosis in tapeworm carriers. Neurology. 1999; 53:1582-84. [PubMed: 10534273]

12. Gemmell, M.; Matyas, Z.; Pawlowsky, Z.; Soulsby, EJL. Guidelines for surveillance and control of Taeniasis/Cysticercosis. World Health Organization; Geneva: 1983.

13. Richards F Jr, Schantz PM. Cysticercosis and taeniasis. N Engl J Med. 1985; 312:787-88. [PubMed: 3974655]

14. Allan JC, Velasquez-Tohom M, Garcia-Noval J, et al. Epidemiology of intestinal taeniasis in four, rural, Guatemalan communities. Ann Trop Med Parasitol. 1996; 90:157-65. [PubMed: 8762405]

15. Allan JC, Velasquez-Tohom M, Torres-Alvarez R, Yurrita P, Garcia-Noval J. Field trial of the coproantigen-based diagnosis of Taenia solium taeniasis by enzyme-linked immunosorbent assay. Am J Trop Med Hyg. 1996; 54:352-56. [PubMed: 8615446]

16. Garcia HH, Gilman RH, Gonzalez AE, et al. Hyperendemic human and porcine Taenia solium infection in Peru. Am J Trop Med Hyg. 2003; 68:268-75. [PubMed: 12685628]

17. Mayta H, Talley A, Gilman RH, et al. Differentiating Taenia solium and Taenia saginata infections by simple hematoxylin-eosin staining and PCR-restriction enzyme analysis. J Clin Microbiol. 2000; 38:133-37. [PubMed: 10618076]

18. Hall A, Latham MC, Crompton DW, Stephenson LS. Taenia saginata (Cestoda) in western Kenya: the reliability of faecal examinations in diagnosis. Parasitology. 1981; 83:91-101. [PubMed: 7196568]

19. Garcia HH, Gilman RH, Horton J, et al. Albendazole therapy for neurocysticercosis: a prospective double-blind trial comparing 7 versus 14 days of treatment. Neurology. 1997; 48:1421-27. [PubMed: 9153484]

20. Allan JC, Avila G, Garcia Noval J, Flisser A, Craig PS. Immunodiagnosis of taeniasis by coproantigen detection. Parasitology. 1990; 101:473-77. [PubMed: 2092303]

21. Gonzalez LM, Montero E, Harrison LJ, Parkhouse RM, Garate T. Differential diagnosis of Taenia saginata and Taenia solium infection by PCR. J Clin Microbiol. 2000; 38:737-44. [PubMed: 10655377]

22. Wilkins PP, Allan JC, Verastegui M, et al. Development of a serologic assay to detect Taenia solium taeniasis. Am J Trop Med Hyg. 1999; 60:199-204. [PubMed: 10072136]

23. Pearson RD, Hewlett EL. Niclosamide therapy for tapeworm infections. Ann Intern Med. 1985; 102:550-51. [PubMed: 3977200]

24. Flisser A, Madrazo I, Plancarte A, et al. Neurological symptoms in occult neurocysticercosis after single taeniacidal dose of praziquantel. Lancet. 1993; 342:748. [PubMed: 8103859] 
25. Garcia HH, Araoz R, Gilman RH, et al. Increased prevalence of cysticercosis and taeniasis among professional fried pork vendors and the general population of a village in the Peruvian highlands. Am J Trop Med Hyg. 1998; 59:902-05. [PubMed: 9886197]

26. Schantz PM, Moore AC, Munoz JL, et al. Neurocysticercosis in an Orthodox Jewish community in New York City. N Engl J Med. 1992; 327:692-95. [PubMed: 1495521]

27. Martinez MJ, De Aluja AS, Gemmell M. Failure to incriminate domestic flies (Diptera: Muscidae) as mechanical vectors of Taenia eggs (Cyclophyllidea: Taeniidae) in rural Mexico. J Med Entomol. 2000; 37:489-91. [PubMed: 10916288]

28. Nash TE, Neva FA. Recent advances in the diagnosis and treatment of cerebral cysticercosis. N Engl J Med. 1984; 311:1492-96. [PubMed: 6390196]

29. Yoshino K. Studies on the post-embryonal development of Taenia solium: III on the development of Cysticercus cellulosae within the definitive intermediate host. J Med Assoc Formosa. 1933; 32:166-69.

30. Dixon HBF, Smithers DW. Epilepsy in cysticercosis (Taenia solium): a study of seventy-one cases. QJM. 1934; 3:603-16.

31. Sahai K, Kapila K, Verma K. Parasites in fine needle breast aspirates-assessment of host tissue response. Postgrad Med J. 2002; 78:165-67. [PubMed: 11884700]

32. Rabiela, MT.; Rivas, A.; Rodriguez, J.; Castillo, S.; Cancino, FM. Anatomopathological aspects of human brain cysticercosis. In: Flisser, A.; Willms, K.; Laclette, JP.; Larralde, C.; Ridaura, C.; Beltran, F., editors. Cysticercosis: present state of knowledge and perspectives. Academic Press; New York: 1982. p. 179-200.

33. Rahalkar MD, Shetty DD, Kelkar AB, Kelkar AA, Kinare AS, Ambardekar ST. The many faces of cysticercosis. Clin Radiol. 2000; 55:668-74. [PubMed: 10988043]

34. Cardenas F, Quiroz H, Plancarte A, Meza A, Dalma A, Flisser A. Taenia solium ocular cysticercosis: findings in 30 cases. Ann Ophthalmol. 1992; 24:25-28. [PubMed: 1543323]

35. Wadia N, Desai S, Bhatt M. Disseminated cysticercosis: new observations, including CT scan findings and experience with treatment by praziquantel. Brain. 1988; 111:597-614. [PubMed: 3382913]

36. Chandra S, Vashisht S, Menon V, Berry M, Mukherji SK. Optic nerve cysticercosis: imaging findings. AJNR Am J Neuroradiol. 2000; 21:198-200. [PubMed: 10669250]

37. Chang GY, Keane JR. Visual loss in cysticercosis: analysis of 23 patients. Neurology. 2001; 57:545-48. [PubMed: 11502934]

38. Evans, CAW.; Cysticercosis Working Group in Peru. The immunology of the host-parasite relationship in Taenia solium cysticercosis: implications for prevention and therapy. In: Garcia, HH.; Martinez, SM., editors. Taenia solium taeniasis/cysticercosis. 2nd edn.. Ed Universo; Lima: 1999. p. 25-37.

39. Carpio A. Neurocysticercosis: an update. Lancet Infect Dis. 2002; 2:751-62. [PubMed: 12467692]

40. McArthur WP. Cysticercosis as seen in the British army with special reference to the production of epilepsy. Trans R Soc Trop Med Hyg. 1934; 27:343-63.

41. Dixon HBF, Hargreaves WH. Cysticercosis (Taenia solium): a further ten years' clinical study, covering 284 cases. QJM. 1944; 13:107-21.

42. Chopra JS, Kaur U, Mahajan RC. Cysticerciasis and epilepsy: a clinical and serological study. Trans R Soc Trop Med Hyg. 1981; 75:518-20. [PubMed: 7324126]

43. Del Brutto OH, Santibanez R, Noboa CA, Aguirre R, Diaz E, Alarcon TA. Epilepsy due to neurocysticercosis: analysis of 203 patients. Neurology. 1992; 42:389-92. [PubMed: 1736171]

44. Garcia HH, Martinez M, Gilman R, et al. Diagnosis of cysticercosis in endemic regions. Lancet. 1991; 338:549-51. [PubMed: 1678809]

45. Carpio A, Hauser WA. Prognosis for seizure recurrence in patients with newly diagnosed neurocysticercosis. Neurology. 2002; 59:1730-34. [PubMed: 12473760]

46. Lobato RD, Lamas E, Portillo JM, et al. Hydrocephalus in cerebral cysticercosis: pathogenic and therapeutic considerations. J Neurosurg. 1981; 55:786-93. [PubMed: 7310501]

47. Sotelo J, Guerrero V, Rubio F. Neurocysticercosis: a new classification based on active and inactive forms: a study of 753 cases. Arch Intern Med. 1985; 145:442-45. [PubMed: 3977513] 
48. Del Brutto OH, Sotelo J, Aguirre R, Diaz-Calderon E, Alarcon TA. Albendazole therapy for giant subarachnoid cysticerci. Arch Neurol. 1992; 49:535-38. [PubMed: 1580817]

49. Proano JV, Madrazo I, Avelar F, Lopez-Felix B, Diaz G, Grijalva I. Medical treatment for neurocysticercosis characterized by giant subarachnoid cysts. N Engl J Med. 2001; 345:879-85. [PubMed: 11565520]

50. Barrinagarrementeria, F.; Cantu, C. Cerebrovascular manifestations of neurocysticercosis. In: Singh, G.; Prabhakar, S., editors. Taenia solium cysticercosis: from basic to clinical science. CABI Publishing; Oxfordshire: 2002. p. 221-28.

51. Rangel R, Torres B, Del Bruto O, Sotelo J. Cysticercotic encephalitis: a severe form in young females. Am J Trop Med Hyg. 1987; 36:387-92. [PubMed: 3826497]

52. Parmar H, Shah J, Patwardhan V, et al. MR imaging in intramedullary cysticercosis. Neuroradiology. 2001; 43:961-67. [PubMed: 11760802]

53. Trelles JO, Rocca ED, Ravens R. Estudios sobre neurocisticercosis: I sobre la fina estructura de la membrana vesicular quística y racemosa, deducciones patológicas. Rev Neuropsiquiatr (Perú). $1952 ; 15: 1-35$.

54. Escobar, A. The pathology of neurocysticercosis. In: Palacios, E.; Rodriguez-Carbajal, J.; Taveras, JM., editors. Cysticercosis of the central nervous system. Charles C Thomas; Springfield: 1983. p. 27-54.

55. Kramer J, Carrazana EJ, Cosgrove GR, Kleefield J, Edelman RR. Transaqueductal migration of a neurocysticercus cyst: case report. J Neurosurg. 1992; 77:956-58. [PubMed: 1432141]

56. Neal JH. An endoscopic approach to cysticercosis cysts of the posterior third ventricle. Neurosurgery. 1995; 36:1040-43. [PubMed: 7791971]

57. Zee CS, Go JL, Kim PE, DiGiorgio CM. Imaging of neurocysticercosis. Neuroimaging Clin N Am. 2000; 10:391-407. [PubMed: 10775958]

58. Bickerstaff ER, Cloake PCP, Hughes B, Smith WT. The racemose form of cerebral cysticercosis. Brain. 1952; 75:1-16. [PubMed: 14916052]

59. Diwan AR, Coker-Vann M, Brown P, et al. Enzyme-linked immunosorbent assay (ELISA) for the detection of antibody to cysticerci of Taenia solium. Am J Trop Med Hyg. 1982; 31:364-69. [PubMed: 7072900]

60. Rosas N, Sotelo J, Nieto D. ELISA in the diagnosis of neurocysticercosis. Arch Neurol. 1986; 43:353-56. [PubMed: 3954618]

61. Tsang VC, Brand JA, Boyer AE. An enzyme-linked immunoelectrotransfer blot assay and glycoprotein antigens for diagnosing human cysticercosis (Taenia solium). J Infect Dis. 1989; 159:50-59. [PubMed: 2909643]

62. Tsang VC, Pilcher JA, Zhou W, et al. Efficacy of the immunoblot assay for cysticercosis in pigs and modulated expression of distinct IgM/IgG activities to Taenia solium antigens in experimental infections. Vet Immunol Immunopathol. 1991; 29:69-78. [PubMed: 1949584]

63. Proano-Narvaez JV, Meza-Lucas A, Mata-Ruiz O, Garcia-Jeronimo RC, Correa D. Laboratory diagnosis of human neurocysticercosis: double-blind comparison of enzyme-linked immunosorbent assay and electroimmunotransfer blot assay. J Clin Microbiol. 2002; 40:2115-18. [PubMed: 12037074]

64. Gekeler F, Eichenlaub S, Mendoza EG, Sotelo J, Hoelscher M, Loscher T. Sensitivity and specificity of ELISA and immunoblot for diagnosing neurocysticercosis. Eur J Clin Microbiol Infect Dis. 2002; 21:227-29. [PubMed: 11957028]

65. Wilson M, Bryan RT, Fried JA, et al. Clinical evaluation of the cysticercosis enzyme-linked immunoelectrotransfer blot in patients with neurocysticercosis. J Infect Dis. 1991; 164:1007-09. [PubMed: 1940452]

66. Garcia HH, Gilman RH, Catacora M, Verastegui M, Gonzalez AE, Tsang VC. Serologic evolution of neurocysticercosis patients after antiparasitic therapy. J Infect Dis. 1997; 175:486-89. [PubMed: 9203680]

67. Estrada JJ, Kuhn RE. Immunochemical detection of antigens of larval Taenia solium and antilarval antibodies in the cerebrospinal fluid of patients with neurocysticercosis. J Neurol Sci. 1985; 71:39-48. [PubMed: 4087018] 
68. Correa D, Sandoval MA, Harrison LJ, et al. Human neurocysticercosis: comparison of enzyme immunoassay capture techniques based on monoclonal and polyclonal antibodies for the detection of parasite products in cerebrospinal fluid. Trans R Soc Trop Med Hyg. 1989; 83:814-16. [PubMed: 2694513]

69. Garcia HH, Harrison LJ, Parkhouse RM, et al. A specific antigen-detection ELISA for the diagnosis of human neurocysticercosis. Trans R Soc Trop Med Hyg. 1998; 92:411-14. [PubMed: 9850394]

70. Garcia HH, Parkhouse RM, Gilman RH, et al. Serum antigen detection in the diagnosis, treatment, and follow-up of neurocysticercosis patients. Trans R Soc Trop Med Hyg. 2000; 94:673-76. [PubMed: 11198654]

71. Garcia HH, Herrera G, Gilman RH, et al. Discrepancies between cerebral computed tomography and western blot in the diagnosis of neurocysticercosis. Am J Trop Med Hyg. 1994; 50:152-57. [PubMed: 8116806]

72. Vasconcelos D. From cyst to cysticercus granuloma using cranial computerized tomography. Gac Med Mex. 1990; 126:401-04. [PubMed: 2103545]

73. Sheth TN, Pillon L, Keystone J, Kucharczyk W. Persistent MR contrast enhancement of calcified neurocysticercosis lesions. AJNR Am J Neuroradiol. 1998; 19:79-82. [PubMed: 9432161]

74. Nash TE, Patronas NJ. Edema associated with calcified lesions in neurocysticercosis. Neurology. 1999; 53:777-81. [PubMed: 10489040]

75. Nash TE, Pretell J, Garcia HH. Calcified cysticerci provoke perilesional edema and seizures. Clin Infect Dis. 2001; 33:1649-53. [PubMed: 11595994]

76. Gupta RK, Kumar R, Chawla S, Pradhan S. Demonstration of scolex within calcified cysticercus cyst: its possible role in the pathogenesis of perilesional edema. Epilepsia. 2002; 43:1502-08. [PubMed: 12460252]

77. Martinez HR, Rangel-Guerra R, Elizondo G, et al. MR imaging in neurocysticercosis: a study of 56 cases. AJNR Am J Neuroradiol. 1989; 10:1011-19. [PubMed: 2505513]

78. Del Brutto OH, Rajshekhar V, White AC Jr, et al. Proposed diagnostic criteria for neurocysticercosis. Neurology. 2001; 57:177-83. [PubMed: 11480424]

79. Kramer LD, Locke GE, Byrd SE, Daryabagi J. Cerebral cysticercosis: documentation of natural history with CT. Radiology. 1989; 171:459-62. [PubMed: 2704811]

80. Cuetter AC, Garcia-Bobadilla J, Guerra LG, Martinez FM, Kaim B. Neurocysticercosis: focus on intraventricular disease. Clin Infect Dis. 1997; 24:157-64. [PubMed: 9114141]

81. Kelley R, Duong DH, Locke GE. Characteristics of ventricular shunt malfunctions among patients with neurocysticercosis. Neurosurgery. 2002; 50:757-61. [PubMed: 11904026]

82. Robles C, Chavarria Chavarria M. Report of a clinical case of cerebral cysticercosis treated medically with a new drug: praziquantel. Salud Publica Mex. 1979; 21:603-18. [PubMed: 550331]

83. Botero D, Castano S. Treatment of cysticercosis with praziquantel in Colombia. Am J Trop Med Hyg. 1982; 31:811-21. [PubMed: 7102916]

84. Sotelo J, Escobedo F, Rodriguez-Carbajal J, Torres B, Rubio-Donnadieu F. Therapy of parenchymal brain cysticercosis with praziquantel. N Engl J Med. 1984; 310:1001-07. [PubMed: 6708975]

85. Escobedo F, Penagos P, Rodriguez J, Sotelo J. Albendazole therapy for neurocysticercosis. Arch Intern Med. 1987; 147:738-41. [PubMed: 3827462]

86. Sotelo J, Escobedo F, Penagos P. Albendazole vs praziquantel for therapy for neurocysticercosis: a controlled trial. Arch Neurol. 1988; 45:532-34. [PubMed: 3358706]

87. Moodley M, Moosa A. Treatment of neurocysticercosis: is praziquantel the new hope? Lancet. 1989; 1:262-63. [PubMed: 2563422]

88. Kramer LD. Medical treatment of cysticercosis-ineffective. Arch Neurol. 1995; 52:101-02. [PubMed: 7826267]

89. Del Brutto OH. Medical treatment of cysticercosis-effective. Arch Neurol. 1995; 52:102-04. [PubMed: 7826268] 
90. Carpio A, Santillan F, Leon P, Flores C, Hauser WA. Is the course of neurocysticercosis modified by treatment with antihelminthic agents? Arch Intern Med. 1995; 155:1982-88. [PubMed: 7575052]

91. Baranwal AK, Singhi PD, Khandelwal N, Singhi SC. Albendazole therapy in children with focal seizures and single small enhancing computerized tomographic lesions: a randomized, placebocontrolled, double blind trial. Pediatr Infect Dis J. 1998; 17:696-700. [PubMed: 9726343]

92. Baranwal AK, Singhi PD, Singhi SC, Khandelwal N. Seizure recurrence in children with focal seizures and single small enhancing computed tomographic lesions: prognostic factors on longterm follow-up. J Child Neurol. 2001; 16:443-45. [PubMed: 11417612]

93. Padma MV, Behari M, Misra NK, Ahuja GK. Albendazole in single CT ring lesions in epilepsy. Neurology. 1994; 44:1344-46. [PubMed: 8035946]

94. Padma MV, Behari M, Misra NK, Ahuja GK. Albendazole in neurocysticercosis. Natl Med J India. 1995; 8:255-58. [PubMed: 8520442]

95. Salinas R, Prasad K. Drugs for treating neurocysticercosis (tapeworm infection of the brain) (Cochrane Review). Cochrane Database Syst Rev. 2003; 2 CD000215.

96. Sotelo J, del Brutto OH, Penagos P, et al. Comparison of therapeutic regimen of anticysticercal drugs for parenchymal brain cysticercosis. J Neurol. 1990; 237:69-72. [PubMed: 2192018]

97. Corona T, Lugo R, Medina R, Sotelo J. Single-day praziquantel therapy for neurocysticercosis. N Engl J Med. 1996; 334:125. [PubMed: 8531958]

98. Pretell EJ, Garcia HH, Gilman RH, Saavedra H, Martinez M, Cysticercosis Working Group in Peru. Failure of one-day praziquantel treatment in patients with multiple neurocysticercosis lesions. Clin Neurol Neurosurg. 2001; 103:175-77. [PubMed: 11532559]

99. Garcia HH, Evans CAW, Nash TE, et al. Current consensus guidelines for treatment of neurocysticercosis. Clin Microbiol Rev. 2002; 15:74-56.

100. Del Brutto OH. Prognostic factors for seizure recurrence after withdrawal of antiepileptic drugs in patients with neurocysticercosis. Neurology. 1994; 44:1706-09. [PubMed: 7936301]

101. Gonzales AE, Garcia HH, Gilman RH, et al. Effective, single-dose treatment or porcine cysticercosis with oxfendazole. Am J Trop Med Hyg. 1996; 54:391-94. [PubMed: 8615453]

102. Gonzalez AE, Falcon N, Gavidia C, et al. Treatment of porcine cysticercosis with oxfendazole: a dose-response trial. Vet Rec. 1997; 141:420-22. [PubMed: 9364715]

103. Gonzalez AE, Falcon N, Gavidia C, et al. Time-response curve of oxfendazole in the treatment of swine cysticercosis. Am J Trop Med Hyg. 1998; 59:832-36. [PubMed: 9840607]

104. Lightowlers MW, Flisser A, Gauci CG, Heath DD, Jensen O, Rolfe R. Vaccination against cysticercosis and hydatid disease. Parasitol Today. 2000; 16:191-96. [PubMed: 10782077]

105. Verastegui M, Gilman RH, Gonzalez AE, et al. Taenia solium oncosphere antigen induces immunity in pigs against experimental cysticercosis. Vet Parasitol. 2002; 108:49-62. [PubMed: 12191899]

106. Gauci CG, Flisser A, Lightowlers MW. A Taenia solium oncosphere protein analogous to hostprotective Taenia ovis and Taenia saginata 18kDa antigens. Int J Parasitol. 1998; 28:757-60. [PubMed: 9650055]

107. Plancarte A, Flisser A, Gauci CG, Lightowlers MW. Vaccination against Taenia solium cysticercosis in pigs using native and recombinant oncosphere antigens. Int J Parasitol. 1999; 29:643-47. [PubMed: 10428641]

108. Schantz PM, Sarti E, Plancarte A, et al. Community-based epidemiological investigations of cysticercosis due to Taenia solium: comparison of serological screening tests and clinical findings in two populations in Mexico. Clin Infect Dis. 1994; 18:879-85. [PubMed: 8086547]

109. Cruz ME, Schantz PM, Cruz I, et al. Epilepsy and neurocysticercosis in an Andean community. Int J Epidemiol. 1999; 28:799-803. [PubMed: 10480714]

110. Garcia-Noval J, Moreno E, de Mata F, et al. An epidemiological study of epilepsy and epileptic seizures in two rural Guatemalan communities. Ann Trop Med Parasitol. 2001; 95:167-75. [PubMed: 11299123]

111. Sanchez AL, Lindback J, Schantz PM, et al. A population-based, case-control study of Taenia solium taeniasis and cysticercosis. Ann Trop Med Parasitol. 1999; 93:247-58. [PubMed: 10562826] 
112. Garcia HH, Gonzalez AE, Gilman RH, et al. Short report: transient antibody response in Taenia solium infection in field conditions-a major contributor to high seroprevalence. Am J Trop Med Hyg. 2001; 65:31-32. [PubMed: 11504404]

113. Verastegui M, Gonzalez A, Gilman RH, et al. Experimental infection model for Taenia solium cysticercosis in swine. Vet Parasitol. 2000; 94:33-44. [PubMed: 11078942]

114. Singh G. Neurocysticercosos in South-Central America and the Indian subcontinent: a comparative evaluation. Arq Neuropsiquiatr. 1997; 55:349-56. [PubMed: 9629348]

115. Cruz M, Davis A, Dixon H, Pawlowski ZS, Proano J. Operational studies on the control of Taenia solium taeniasis/cysticercosis in Ecuador. Bull World Health Organ. 1989; 67:401-07. [PubMed: 2805217]

116. Garcia-Noval J, Allan JC, Fletes C, et al. Epidemiology of Taenia solium taeniasis and cysticercosis in two rural Guatemalan communities. Am J Trop Med Hyg. 1996; 55:282-89. [PubMed: 8842116]

117. Gonzalez AE, Cama V, Gilman RH, et al. Prevalence and comparison of serologic assays, necropsy, and tongue examination for the diagnosis of porcine cysticercosis in Peru. Am J Trop Med Hyg. 1990; 43:194-99. [PubMed: 2389823]

118. The Cysticercosis Working Group in Peru. The marketing of cysticercotic pigs in the Sierra of Peru. Bull World Health Organ. 1993; 71:223-28. [PubMed: 8490986]

119. Garcia HH, Gilman RH, Gonzalez AE, Pacheco R, Verastegui M, Tsang VC. Human and porcine Taenia solium infection in a village in the highlands of Cusco, Peru. Acta Trop. 1999; 73:31-36. [PubMed: 10379814]

120. Nicoletti A, Bartoloni A, Reggio A, et al. Epilepsy, cysticercosis, and toxocariasis: a populationbased case-control study in rural Bolivia. Neurology. 2002; 58:1256-61. [PubMed: 11971095]

121. Placencia M, Sander JW, Shorvon SD, Ellison RH, Cascante SM. Validation of a screening questionnaire for the detection of epileptic seizures in epidemiological studies. Brain. 1992; 115:783-94. [PubMed: 1628202]

122. Jimenez I, Mora O, Uribe CS, et al. Factores de riesgo en epilepsia: estudio epidemiologico de cass y controles. Acta Medica Colombiana. 1991; 16:5-14.

123. Osuntokun BO, Schoenberg BS. Research protocol for measuring the prevalence of neurological disorders in developing countries: results of a pilot study in Nigeria. Neuroepidemiology. 1982; $1: 143-53$.

124. Naidoo DV, Pammenter MD, Moosa A, van Dellen JR, Cosnett JE. Seventy black epileptics: cysticercosis, computed tomography and electro-encephalography. S Afr Med J. 1987; $72: 837$ 88. [PubMed: 3424029]

125. Garcia HH, Gilman R, Martinez M, et al. Cysticercosis as a major cause of epilepsy in Peru. Lancet. 1993; 341:197-200. [PubMed: 8093496]

126. Flisser A. Neurocysticercosis in Mexico. Parasitol Today. 1988; 4:131-37. [PubMed: 15463066]

127. Medina MT, Rosas E, Rubio-Donnadieu F, Sotelo J. Neurocysticercosis as the main cause of lateonset epilepsy in Mexico. Arch Intern Med. 1990; 150:325-27. [PubMed: 2302008]

128. Garcia HH, Gilman RH, Tsang VC, Gonzalez AE. Clinical significance of neurocysticercosis in endemic villages. Trans R Soc Trop Med Hyg. 1997; 91:176-78. [PubMed: 9196761]

129. Ong S, Talan DA, Moran GJ, et al. Neurocysticercosis in radiographically imaged seizure patients in US emergency departments. Emerg Infect Dis. 2002; 8:608-13. [PubMed: 12023918]

130. Dietrichs E, Tyssvang T, Aanonsen NO, Bakke SJ. Cerebral cysticercosis in Norway. Acta Neurol Scand. 1993; 88:296-98. [PubMed: 8256577]

131. Roman G, Sotelo J, Del Brutto O, et al. A proposal to declare neurocysticercosis an international reportable disease. Bull World Health Organ. 2000; 78:399-406. [PubMed: 10812740]

132. Acevedo, A. Economic impact of porcine cysticercosis. In: Flisser, A.; Willms, K.; Laclette, JP.; Larralde, C.; Ridaura, C.; Beltran, F., editors. Cysticercosis: present state of knowledge and perspectives. Academic Press; New York: 1982. p. 63-68.

133. Murrell KD. Economic losses resulting from food-borne parasitic zoonoses. Southeast Asian J Trop Med Public Health. 1991; 22(suppl):377-81. [PubMed: 1822931] 
134. Bern C, Garcia HH, Evans C, et al. Magnitude of the disease burden from neurocysticercosis in a developing country. Clin Infect Dis. 1999; 29:1203-09. [PubMed: 10524964]

135. Gilman, R.; Garcia, HH.; Gonzalez, AE., et al. Short cuts to development: methods to control the transmission of cysticercosis in developing countries. In: Garcia, HH.; Martinez, SM., editors. Taenia solium taeniasis/cysticercosis. 2nd edn.. Ed Universo; Lima: 1999. p. 313-26.

136. Schantz PM, Cruz M, Sarti E, Pawlowski Z. Potential eradicability of taeniasis and cysticercosis. Bull Pan Am Health Organ. 1993; 27:397-403. [PubMed: 8312963]

137. Allan JC, Velasquez-Tohom M, Fletes C, et al. Mass chemotherapy for intestinal Taenia solium infection: effect on prevalence in humans and pigs. Trans R Soc Trop Med Hyg. 1997; 91:59598. [PubMed: 9463679]

138. Sarti E, Flisser A, Schantz PM, et al. Development and evaluation of a health education intervention against Taenia solium in a rural community in Mexico. Am J Trop Med Hyg. 1997; 56:127-32. [PubMed: 9080868]

139. Sarti E, Schantz PM, Avila G, Ambrosio J, Medina-Santillan R, Flisser A. Mass treatment against human taeniasis for the control of cysticercosis: a population-based intervention study. Trans $\mathrm{R}$ Soc Trop Med Hyg. 2000; 94:85-89. [PubMed: 10748908]

140. Gonzalez AE, Gavidia C, Falcon N, et al. Protection of pigs with cysticercosis from further infections after treatment with oxfendazole. Am J Trop Med Hyg. 2001; 65:15-18. [PubMed: 11504400]

141. Huerta M, de Aluja AS, Fragoso G, et al. Synthetic peptide vaccine against Taenia solium pig cysticercosis: successful vaccination in a controlled field trial in rural Mexico. Vaccine. 2001; 20:262-66. [PubMed: 11567772]

142. Lightowlers MW, Gauci CG. Vaccines against cysticercosis and hydatidosis. Vet Parasitol. 2001; 101:337-52. [PubMed: 11707305] 


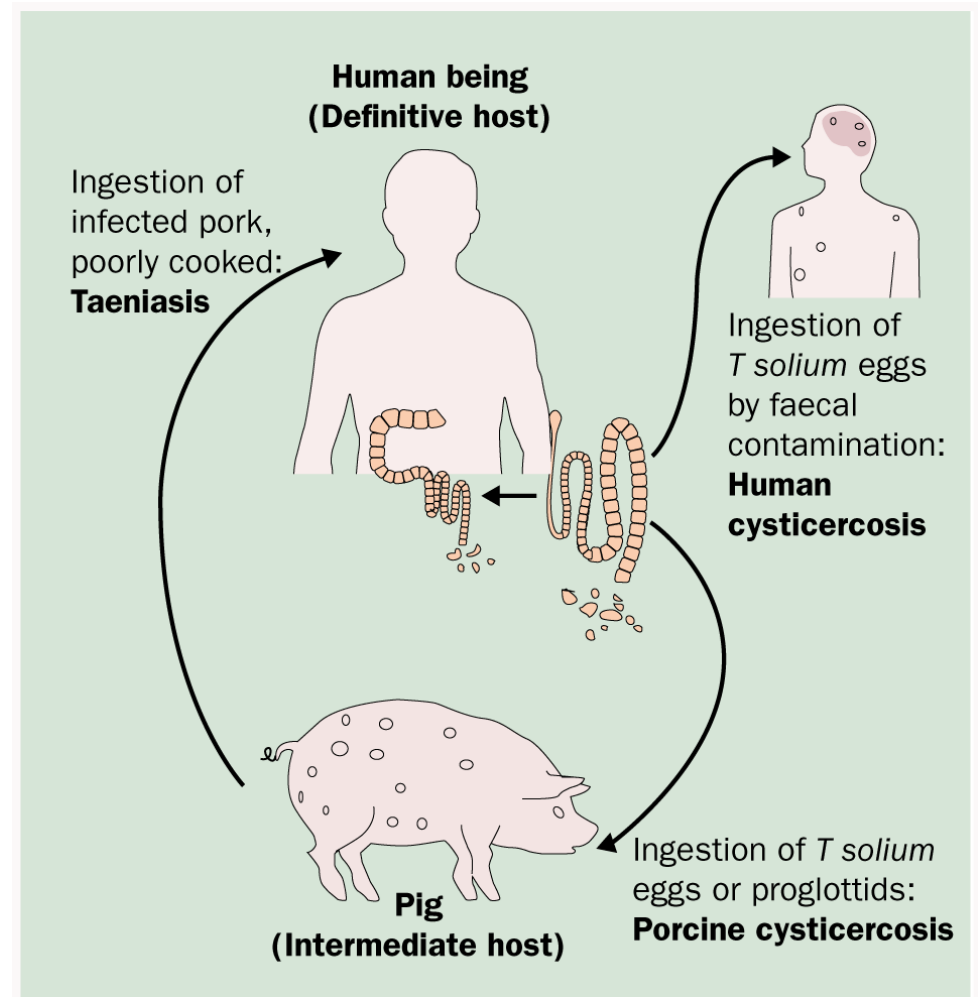

Figure 1.

Life cycle of Taenia solium 

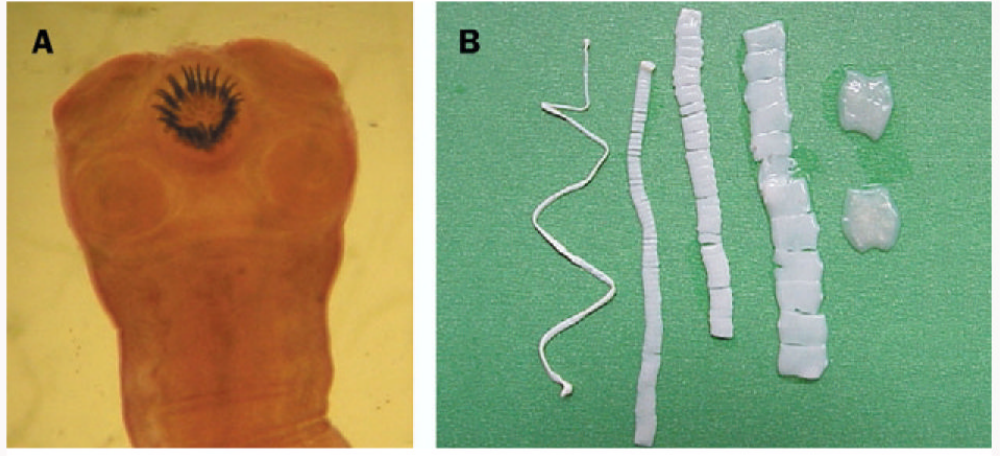

Figure 2. Scolex (A) and strobila (B) of adult tapeworm

The morphology of the proglottids changes as they mature and become gravid. 

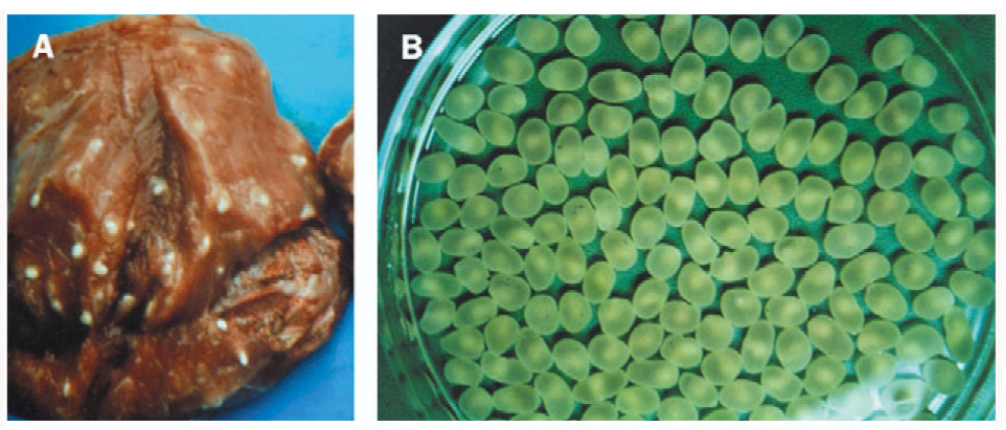

Figure 3. Cysticerci

(A): as seen in infected pork. (B): excised into a Petri dish. The white dot in each cyst corresponds to the scolex. 

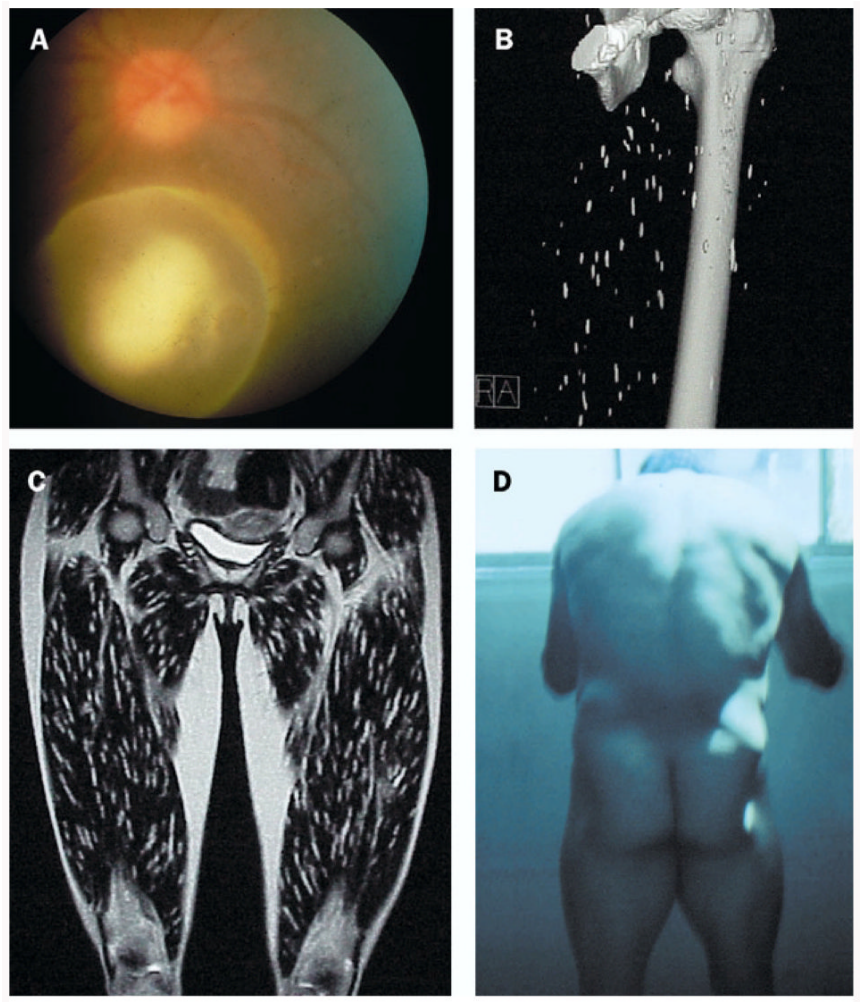

Figure 4. Cysticercosis outside the nervous system

(A): ocular cyst floating in the vitreous humour. (B): calcified cysts on CT (threedimensional filtered reconstruction). (C) and (D): massive infection causing muscular pseudohypertrophia; thousands of cysts following the muscle planes can be seen. 

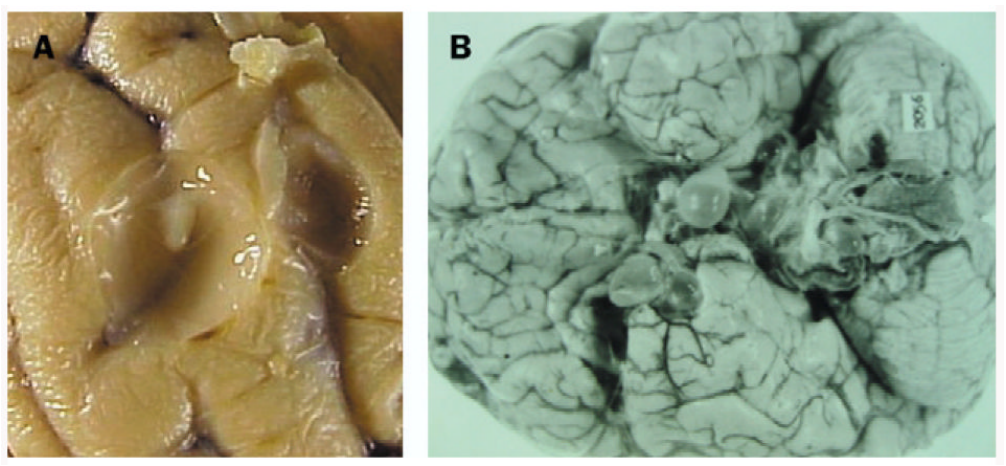

Figure 5. Macroscopic pathology

A: viable cyst. B: racemose cysticercosis in the base of the brain. 


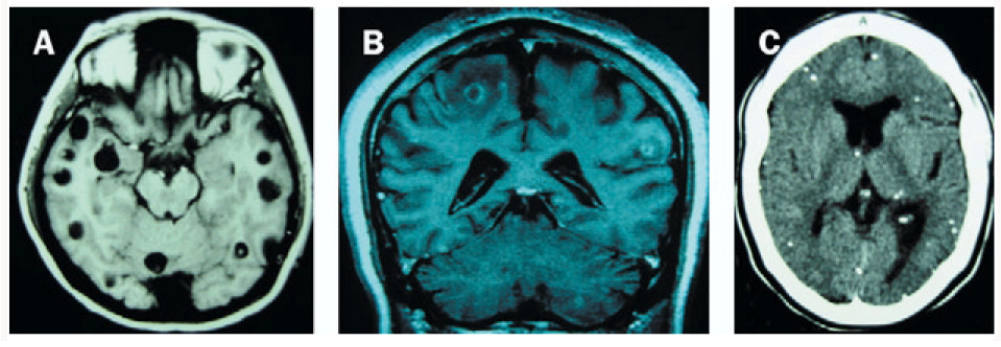

Figure 6. Neuroimaging

MRI of viable (A) and degenerating (B) cysts, and CT of calcified cysticerci (C). 